\title{
Library Gateway: Project Design, Teams, and Cycle Time
}

\section{Karen Calhoun, Zsuzsa Koltay, and Edward Weissman}

\begin{abstract}
Librarians at Cornell University Library (CUL) launched the first systemwide integrated gateway to networked resources, services, and library information in January 1998. The system was created and introduced in just 17 weeks. The Library Gateway was launched in response to a confusing CUL online presence; the library was spending half a million dollars a year on online resources and devoting a substantial amount of staff time to provide access to them, but systemwide efforts were only loosely coordinated. In this article, we examine the design and implementation process that helped the project succeed, rather than focusing on the technology or the vision behind the gateway. Examining the gateway project as a case study of new product development, we identify and discuss critical success factors, including: starting with a clearly defined concept, the importance of buy-in, simultaneous development of different portions of the project, employing cross-functional teams, and seeking continual feedback. Working together on a project of this complexity and on such a fast time line was an important organizational learning experience that moved CUL a step closer to mastering the process of innovation.
\end{abstract}

T (htp://campusguliver ure 1) represents the first integrated approach to providing Web-based information services to the Comell community, and as such its introduction in January 1998 was an important step forward. Yet the process by which the gateway was implemented was equally important to the library, whose managers and staff continually are striving to deliver new services as quickly and cost-effectively as possible. It has become critical to know, from an organizational perspective, what enhances the ability to deliver new services in time, on time.
In this paper, we examine the gateway project as a case study of project design, teams, and rapid cycle time. While the technology of the gateway might not be transferable to other environments, the cross-functional process employed to introduce it can serve as a model for others. We favor not merely reconciling, but tightly integrating the work of technical service librarians, public service librarians, collection development librarians, and information technology specialists to solve mission-critical problems and to ensure the continuing success of the library.

Karen Calhoun (ksc10@cornell.edu) is Head of Mediation Services, Central Technical Services, Cornell University Library, Ithaca, New York. Zsuzsa KolTAY is Public Services Librarian, Mann Library, Cornell University Library. EDWAnd WEIssman is Assistant to the University Librarian, Cornell University Library. Manuscript received October 22, 1998; accepted for publication December 11, 1998. 


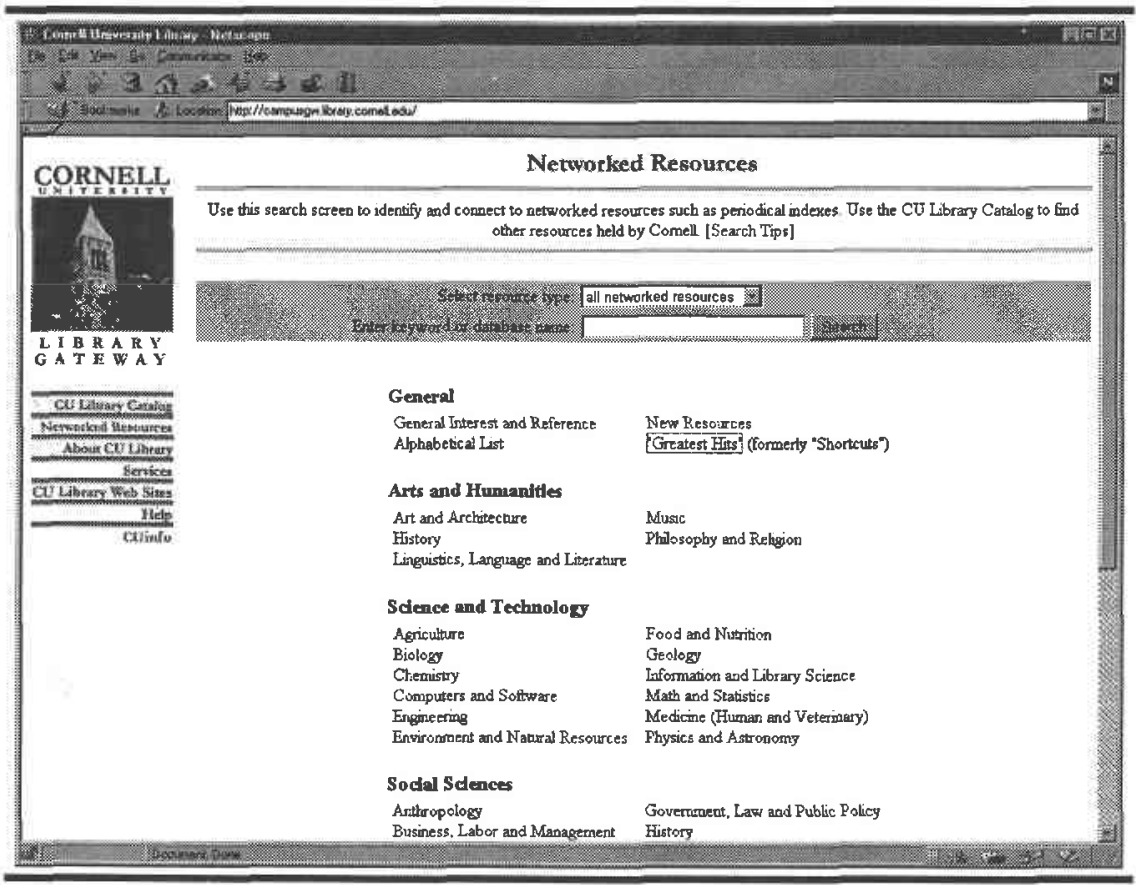

Figure 1. The Cornell University Library Gateway.

We are in a period of turmoil. Electronic resources have turned library practices upside down. The tried-and-true practice of organizing libraries into fairly independent functional groups (collection development, public services, technical services, and information technology) no longer yields acceptable results. For example, Duranceau (1997) compares the workflows of print and electronic, networked serials and concludes, "The print purchase process is a short, straight garden path. The digital world is cyclical... communication, coordination, and team effort is required at almost every stage ... [and] the purchase process is a long, complex, winding dirt road filled with potholes." Schroeder (1997) describes the potential benefits of blurring territorial lines between public and technical service librarians. Martin (1996) emphasizes the importance of healing the schism between technical and public services, and argues that the electronic library provides a tremendous opportunity for public and technical service librarians to begin to share leadership roles.

\section{Context of the Gateway Project}

In 1868 Ezra Cornell, a plainspoken inventor inspired by egalitarian ideals, founded "an institution where any person can find instruction in any study," including not only the arts and sciences, but also applied technology and agriculture (Cornell 1999). Today, the 19 libraries of the Cornell University Library (CUL) system serve 7 undergraduate colleges and schools, 4 graduate and professional units, and 2 medical units. The hallmarks of this complex library system, which employs more than 500 people, are diversity, excellent collections, and a history of semiautonomy for unit libraries.

Until the late 1980s, CUL had a largely captive audience for its print collections of more than $6,000,000$ printed volumes and more than 60,000 journals. Since then, the Internet has altered dramatically library users' perceptions and preferences for obtaining information of all kinds. Based on the experience of many reference librarians and the findings of a campus survey, an important shift in atti- 
tude has occurred: students tend to perceive the effort of using print resources as higher than finding the information online.

In the present dynamic environment, librarians in CUL unit libraries have committed themselves to keeping pace with technological innovations and with their users' preferences for finding information. By early 1997, the 19 CUL libraries had mounted numerous separate "official" library Web sites to provide Web or telnet access to more than 900 online resources. The library was spending half a million dollars a year on online resources, and staff devoted a substantial amount of time to providing access to them, but system-wide efforts were only loosely coordinated.

Organizationally, CUL staff have tended to interpret their roles and responsibilities in two dimensions: (1) with respect to their function (collection development, technical services, public services, information technology) and (2) with respect to the library unit for which they work. The conventional framework for accomplishing large systemwide projects, such as the selection of a new library management system, has been to organize functional committees, with representatives from various library units, to look after each function's and unit's needs. Coordination and conflict management across functions and units have tended to occur at the administrative level.

\section{The Problem}

The result of the technical, service, and organizational environment was a confusing CUL online presence. Networked databases, numeric files, and full-text resources were available but often difficult for users to find. The library was providing three different approaches to these materials.

The first of these was Bear Access, a site based on Mandarin technology developed by Cornell Information Technologies, which presented a set of "launch pads" and "buttons." The buttons represented both specific networked resources (which opened specific sessions or resources), and additional compilations of resources-either more launch pads and buttons or Web pages that provided links to specific networked resources. To discover and access a particular resource, however, users needed to know either the genre (e.g., abstract, index, electronic journal, catalog) or where in the hierarchy the specific pointer to the resource existed. Library staff in the unit libraries supporting the humanities, social sciences, and area studies tended to rely most on the Bear Access model for connecting users to online resources.

The second approach was the Mann Library Gateway, which was developed by the staff at the Albert R. Mann Library, the unit library that supports agriculture, biology, nutrition, human ecology, and related fields. This gateway began as a text-based product but evolved into a Web-based product. Its initial goal was to provide a search engine that allowed users to key in either the name of a resource or keyword terms in order to retrieve descriptions of matching networked resources. Connections to the resources were embedded in the descriptions.

Finally, unit library Web pages gave several unit libraries strong Web presences of their own, among them the hotel management school, the industrial and labor relations school, and the graduate school of business. Here again, to find and use an online resource, the user needed to know something about the cubbyhole in which the resource was located.

Importantly, none of these approaches encompassed all of CUL's networked resources. Users at Mann Library were presented with the Mann Gateway on the public access workstations. Users at most of the other libraries were presented with Bear Access menus. Although the library staff realized that a unified approach-a single point of entry to CUL's networked resources, or a "common entryway"- - was needed, there was no consensus on the best way to achieve it.

There was at least one point of agreement however. With the rapid and continuing growth of networked resources, everyone felt that users should have the option to search as well as browse for networked resources. Library managers and 
staff therefore desired a catalog that incorporated records for networked resources with embedded Uniform Resource Locators (URLs), but they supported two different options. One was to adapt the Mann Gateway technology into a CUL-wide service. The second was to develop a robust and flexible Web front end to the CUL online catalog while at the same time creating the capability of searching that slice of the library catalog that represented networked resources.

In June 1997, the library administration appointed a small committee-the Common Entryway Committee-to review the two common entryway models; evaluate the functions, features, and implementation details for each option; and to recommend a model for CUL. By the end of July 1997, with the assistance of a number of library staff from across CUL, the committee submitted its recommendation to the library administration for the adoption of the Mann Gateway technology and the creation of a CUL Library Gateway.

\section{The Solution}

In late summer 1997, the library administration accepted the recommendations of the Common Entryway Committee and formed three committees to build the Library Gateway over the course of the fall semester. In addition, two programmers - a specialist in HyperText Markup Language (HTML), and a specialist in database work, CGI scripts, Java scripts, connection scripts, and staff interfaces-were assigned full time to the project.

A Public Services Design Committee was charged with designing the CUL common entryway and associated pages. A Technical Services Implementation Committee was formed to provide an approach for browsing networked resources by subject, to develop procedures for gateway record creation and maintenance, and to prepare the Library Gateway database. To coordinate the work of the two implementation committees and provide project oversight, the Library Gateway Steering Committee was appointed.

The steering committee was a crossfunctional group that included the chairs of the two implementation committees, the heads of two information technology departments in the library (the Library Technology Department, which served many of the unit libraries, and Mann Library's Information Technology Section), the associate university librarian for information technology, and the head of the reference department in the largest CUL unit library. While the contributions of all committee members were important to the process, the core project team consisted of the chair of the steering committee, the chairs of the two implementation committees, and the two programmers assigned to the project.

The project was intended to accomplish five objectives:

- To create a unified, identifiable online presence for CUL

- To create a common entryway to CUL's networked resources and services

- To develop and elicit the use of a common set of processes and procedures for cataloging networked resources

- To develop and elicit the use of a common set of processes and procedures for user training and support

- To improve coordination between CUL's two information technology departments

The first meeting of the steering committee was in early September 1997. The project team adopted an extremely ambitious implementation time frame, and committed themselves to bringing up the Library Gateway in 17 weeks (that is, by early 1998). All of the subgroups worked in parallel, with the steering committee providing oversight. The milestones are given in table 1.

The team introduced the Library Gateway on schedule on January 5, 1998, several weeks before the start of the second semester of the academic year.

\section{Project Costs}

Library Gateway development from the start of the fall semester to the launch required about 2,900 hours of staff time, which are listed in table 2.

The gateway had a strong impact on li- 
TABLE 1

Gateway Project Milestones

Subgroup

Information Technology

Technical Services Implementation Committee

Public Services Design Committee

Steering Committee

\section{Milestones}

Determined hardware, software, and manpower requirements; created a Web interface to the MySQL database, which supports searching and display of CUL networked resources; installed the hardware; produced software documentation; loaded the Gateway software onto the server; trained technical support staff; and worked with the two implementation committees to create the necessary Web pages, CGI scripts, PERL scripts, a staff interface to support database creation and maintenance, and other developments.

Developed a scheme for browsing Gateway resources by subject; prepared guidelines for cataloging Gateway resources and trained CUL catalogers to use them; worked with the information technology staff to test the staff interface to the Gateway; and created catalog records for the 1,100 Gateway resources.

Decided on the specific services to be supported on the Gateway and created the design for the screens; implemented the Web pages and designed the pages that are generated by the PERL scripts; and worked closely with the information technology staff to define the final look and feel of the Gateway; wrote the content for help and informational pages.

Prepared recommendations with regard to Cornell and CUL systems, hardware and software that would be affected by the Gateway (e.g., Bear Access); gave numerous presentations on the Gateway to solicit feedback from CUL functional groups; oversaw the incorporation of staff feedback into the Gateway design; drew up plans for public services staff orientation to the Gateway; and completed a plan for ongoing Gateway maintenance and enhancement. brary staff, who had to support the new system, which was not a trivial addition to their usual tasks. Training library staff meant involving most of the organization in maintaining the gateway on some level. Prior to the launch, a task force for gateway training and user support was formed, and the chair became a member of the steering committee. This group put in place a structure and process for handling questions that arrived at reference desks and via e-mail using the "Reference Question?", "Problem Connecting?", and "Comments about the Gateway?" links at the bottom of most gateway pages. The task force also designed and carried out numerous library staff and user training sessions. This group's work had the dual benefits of preparing staff and users for the gateway and of widening the circle of stakeholders in the gateway's future.

\section{The Process: What Was Learned}

To maintain the library's attractiveness to readers and its centrality to the university, staff at CUL have committed themselves to offering efficient, quality access to online resources of interest to their users. To that end, a surprising new organizational competency is required: CUL must be the sort of organization that can design and bring up new online systems and services swiftly and effectively. Further, CUL is faced with mastering the process of innovation and new product development in general-not unlike organizations in the commercial sector.

Researchers in the area of new product management (see, for example, Crawford 1997; Cooper 1993; Cooper and Kleinschmidt 1993) suggest that the ability to innovate and deliver a steady 
TABLE 2

Gateway Project Costs

Group Staff Hours (Estimate)

Information Technology Staff

1,350

Technical Services Implementation Committee

650

Public Services Design Committee

625

Steering Committee

Total

2,900

stream of new products is essential to an organization's growth and long-term viability. Along the same lines, reduced cycle time-speed to market-appears to be central to an organization's continued success in its market. The experience with the Library Gateway project indicates that there may be some key ideas to success for introducing new products in large, organizationally complex organizations such as CUL.

The first key idea is to start with a well-developed, clearly defined concept of the new product (which could be a new system or service, like the gateway). Make sure that management and those who must implement the new product understand and buy into the concept. The Library Gateway group was fortunate to begin its work with a well-developed prototype based on the Mann Library Gateway. And, thanks to decisions by the library administration in response to the work of the Common Entryway Committee during the summer of 1997, the implementation groups knew they had the unqualified support of CUL's leadership.

The gateway prototype and its later iterations were valuable communication tools and guides for various individuals and functional groups in the CUL system that needed to buy into the product concept. As a result, everyone involved was reasonably clear about what the Library Gateway would be from the beginning of the project. Without such sharp, early definition of the gateway, the implementation groups might have faced vague or moving targets, or failed to gain the necessary acceptance, and the project might have taken too long-or worse, have not been completed at all.
The second key idea is to undertake a new product development project in a set of simultaneous, overlapping activities, rather than developing in phased, sequential stages. After the selection of a model for the Library Gateway, all of the implementation groups were formed at once and charged with various aspects of the work. Interface design occurred concurrently with gateway database development, technical development, staff training, and marketing (in the sense of gaining awareness and support from those who would be affected by the gateway). The process might have looked chaotic from the outside but it was not. It required a great deal of cross-functional communication, tolerance for ambiguity, management support, and project team commitment to the project, but the concurrent operations enabled the implementation groups to deliver the gateway to library users in only 17 weeks.

The third key idea is to break down organizational barriers by using crossfunctional teams that are interdependent and accountable for the project. The Library Gateway Steering Committee was a cross-functional group that included administrators and staff from various functional areas of the library system (information technology, public services, and technical services). The chairs of the two implementation subcommittees (which were not cross-functional in nature) were part of the steering committee. The steering committee was effective because members were committed to the project; diverse ideas and open communication were encouraged, several team members shared initiative, and team resources were identified and used to good 
purpose. Without this cross-functional structure, the project could have experienced lengthy delays and foul-ups due to the inherent difficulties of passing off responsibility in sequential phases from one compartmentalized functional group to the next.

The final key idea is to seek continual feedback from stakeholders, be responsive to their concerns, and build organizational consensus as the project progresses. The gateway group did its work in the open. While speed was one of the requirements of the project, the team did not allow the gateway project to gather uncontrolled momentum. In other words, as the gateway was developed, team members proactively identified stakeholders-people who needed to know about the project, people who would have to support the gateway once implemented, and people whose approval was needed-and organized demonstration sessions to gather their feedback and advice, uncover and deal with resistance, and gain stakeholders' acceptance of the system. Several times during the course of the project, developers were able to prototype changes to the system within a day or two of receiving a suggestion in one of the demonstration sessions. This responsiveness did a great deal to enhance the project team's credibility and build confidence in the product.

There is evidence that crossfunctional teams can produce dramatic benefits, such as rapid project completion, more innovative services, better quality, and improvements in productivity. Unfortunately, simply creating a team and promoting teamwork does not appear to be sufficient to reap these benefits. For true teamwork to materialize, the team should be the right size, its members must be committed to (and accountable for) the project, and the team must have sufficient autonomy and adequate resources to accomplish its work. Further, there is evidence that effective teams rely on shared decision making, consensus building, and frequent communications with stakeholders to manage organizational boundaries and overcome obstacles (see, for example,

\section{Ranney and Deck 1995).}

Except as stakeholders, CUL collection development and acquisitions staff did not participate in the design and implementation of the gateway. This turned out to be a weakness in the project design. Toward the end of the project, the steering committee conducted a post-project evaluation, and recommended the creation of a crossfunctional Electronic Resources Committee with responsibility for policy and procedural decisions associated with selecting and incorporating new networked resources into the gateway.

By summer 1998, the initial steering committee, the two implementation committees, the task force on training and user support, and the rest of the project team had disbanded. The steering committee's final action was to produce a "mainstreaming document" in which, among other things, it was recommended that a successor group be appointed - the CUL Gateway Committee-that complements the work of the Electronic Resources Committee. The Gateway Committee is made up of a coordinator, the gateway Web editor, the editor of the guidelines for cataloging networked resources, the associate university librarian for library information technology, a technical specialist, a public services librarian, and the chair of the Electronic Resources Committee. The CUL Gateway Committee's charge is to ensure that the gateway continues to evolve to best serve the needs of CUL and its users.

\section{BENEFITS OF THE GATEWAY}

\section{BENEFITS FOR USERS}

With the creation of the gateway, Cornell University built a virtual branch library on the Internet. By pulling all network accessible resources, services, and library information together into a single interface, CUL created an all-inclusive Web presence. Users have a single system to go to instead of having to know ahead of time what they need and where they can find it. Using the library has become easier, and networked resources have become more visible. At the same time, the gateway 
supports and points to the Web sites of unit libraries, thus highlighting and taking advantage of the talent, initiative, and diversity of these libraries.

The gateway was released in early January 1998 , in the middle of the academic year. To make the transition to the new system easier the project team decided to maintain the old-style access for a semester, in tandem with the gateway. Despite this dual environment, the gateway received heavy use all over campus. In January 1998 , there were 12,106 connections; one month later, total connections had jumped to 26,610 . In September 1998, total connections were 48,105 .

Another major benefit is the fact that the gateway has made remote use of CUL resources possible. Because of the authentication and authorization module of the system, it is not necessary to limit access to most of the CUL licensed databases to Cornell-based computers only. Now there is a way to screen users coming from non-Cornell machines and determine who is authorized to have access. This is a major benefit for travelling Cornellians.

\section{ORGANIZATIONAL BENEFITS FOR CUL}

Working on the implementation of the gateway was a shared project across the unit libraries and across functional groups. Working together on a common project of this complexity and on such a short timeline was a very important step towards creating greater understanding and cooperation between functional groups and among the unit libraries. The process affected not only the key players; along the way the gateway project team had to communicate with the wider library community regularly and build its feedback and ideas into the system. The openness and responsiveness of the process helped build trust and acceptance for the gateway in library staff, some of whom were quite reluctant and even resentful of the change at the beginning of the project.

Even after the implementation, the gateway project continues to foster dialog and cooperation. The maintenance of the system requires constant input from and dialog between different functional units of the library (collection development, acquisitions, cataloging, public services, and information technology) and between the main and unit libraries. Openness to suggested improvements and criticism continues to be important.

The library's investment in its online resources is half a million dollars a year. Making these resources more readily accessible and more visible maximizes the benefits of this substantial investment.

\section{The Future}

The library administration has funded a series of focus groups to provide CUL managers and staff with more feedback on the system and more general information about what features the users value and need. The results of this study should prove useful for the development of future generations of the gateway as well.

\section{SUMMARY}

While the Library Gateway is an important technological achievement, what might be most helpful to other institutions is an understanding of the process used to build it. First, the experience with using teams was an excellent one. The cross-functional steering group and its two subgroups were able to cut across traditional organizational boundaries, to work and respond quickly, and to build consensus continuously. Second, but equally important, was the library management's support. By providing a clear mandate and strong sponsorship while still giving the team sufficient autonomy, CUL's leaders established the conditions in which innovation, teamwork, and excellent service could emerge. Third, the critical importance of involving all functional groups in the task of organizing electronic resources in libraries was demonstrated. In the face of the dramatic shift brought about by the Web, it is essential to integrate library functions effectively, and to make the most of what each group knows and does best. 


\section{WORKS CITED}

Cooper, Robert G. 1993. Winning at new products: accelerating the process from idea to launch. Reading, Mass.: Addison-Wesley.

Cooper, Robert G. and Elko J. Kleinschmidt. 1993. Uncovering the keys to new product success. EMR (Winter): 5-18.

Cornell University. 1999. Cornell's mission and values. Online. Available: http://www. info.cornell.edu/CUYHomePage/Mission. html. February 23, 1999.

Crawford, C. Merle. 1997. New products management. Chicago: Irwin.

Duranceau, Ellen Finnie. 1997. Beyond print: revisioning serial acquisitions for the digital age. Online. Available: http://web.mit. edu/waynej/www/duranceau.htm. September 21, 1998.

Martin, Lyn Elizabeth M. 1996. Keeping "Kutta" at bay: the leadership role of the technical services department. Technicalities 16, no. 9: 1, 5-6, 15-16.

Ranney, Joyce and Mark Deck. 1995. Making teams work. Planning review 23, no 4: 6-12.

Schroeder, Penny. 1997. ALA Midwinter Conference 1997: ALCTS Roles of the Professional in Technical Services Discussion Group. Library acquisitions: Practice and theory 21: 475-77.

\section{INDEX TO ADVERTISERS}

Library Technologies

Archival Products

ALCTS

OCLC
$2 \mathrm{~d}$ cover 